\title{
Treacherous Ascents: On Seeking Common Ground for Conflict Resolution
}

\section{Christian Campolo}

\author{
Hendrix College
}

\begin{abstract}
Résumé: Le jugement des penseurs compétents de ne pas employer la raison pour résoudre des désaccords se ronge lorsque ceux-ci adoptent la stratégie populaire d'élever un débat à des plus hauts niveaux de généralité. Cette stra-tégie encourage ceux qui sont en désac- cord de croire-souvent incorrecte-ment-qu'ils se trouvent sur un terrain commun à partir duquel ils peuvent se mettre d'accord. Mais si on suppose régulièrement qu'on partage des valeurs et des intérêts avec nos adversaires dans un conflit apparemment difficile à résoudre, on risque de perdre I'habilité de juger si on en partage assez. Lorsqu'on ne tient plus compte des différences entre les conditions favorables ou défavorables au raisonnement, on finit par avoir tendance à raisonner aux mauvais moments. De tels raisonnements peuvent en retour nuire sérieusement aux habiletés de raisonner.
\end{abstract}

Keywords: Reasoning, conflict resolution, common ground, competence, deep disagreement

\section{Introduction}

This paper is about a popular strategy for dealing with impasses we reach when reasoning together. Instead of advising disputing parties to stop trying to reason together, we sometimes urge them to recognize that at some higher level of generality they can find common ground. We maintain that if we can get them to ascend to this common ground, they may come to see that they share some values, and that their dispute really stems from the fact that they interpret these shared values in different ways. This recognition, we claim, may help them to understand each other better, and therefore to go some way towards resolving their differences.

My claim is that this strategy is actually a high-stakes gamble in the sense that it involves a tacit reliance on improbable assumptions, and in the sense that it places at risk the very skills we employ when we reason. In other words, as strategies go, it is fairly far-fetched and dangerous. 


\section{Examples}

Let me very briefly mention two examples:

In Life's Dominion, Ronald Dworkin (1994; See also Warnke, 1999) elegantly argues that when it comes to the issue of abortion, pro-lifers and pro-choicers only seem to have radically incompatible views. When we examine matters closely we find that their opposing views flow from the same general principle, namely, an appreciation for the sanctity of life. Their real difference stems from the different ways that they interpret this shared, general principle. The real question is not about whether or not a fetus is a person, it is about how best to honor the sanctity of life.

In his paper, "The Ethics of Animal Research: What are the Prospects for Agreement?" David DeGrazia (1999) argues that those who oppose the use of animals in biomedical research and those who favor such use actually have several overarching principles in common. They all agree, for example, that in the absence of competing human interests, many kinds of animals have interests that we ought to protect if we can. The real question is not about whether or not animals have interests we ought to protect; it is about how we ought to weigh those interests against human interests.

I single these examples out not because they deserve any special criticism. In them we can easily see the strategy that I am talking about, a strategy that we will almost always find employed where the best intentions meet up with highly charged debates.

\section{Reasoning Together}

The worry I have about this sort of approach to disagreement comes from a particular view about what reasoning is and how it works (See Wright, 1995, 1999, 2001, 2002; Campolo and Turner, 2002). On this view, reason-giving is a complex activity that depends upon a variety of resources and skills. One of the resources is our general understanding of things, to put it roughly. One of the skills is our ability to articulate parts of that understanding in the form of claims and support for those claims. Reasoning together is, among other things, a way of responding to the sense that we need to repair or establish intersubjectivity. Or to put it another way, it is a way of restoring or initiating purposeful coordination to our several actions or behaviors. We exchange reasons, assess conclusions, to get to, or back to, a state in which we can go on together. We feel compelled to reason together when something we're doing together is at stake. Whenever we discover a need to reason together the appropriate question is not simply "What do we do now?" but rather, "What do we do next in order to continue along together in the smooth manner we were enjoying before?" Reasoning together is about figuring out how to proceed together beyond some interruption. As we'll see below, we will be quite limited in our joint reasoning if we cannot see ourselves as having been engaged in something that got interrupted. By the same token, if we should come to see ourselves as having been engaged in something together when we in fact were not, we will be in just as difficult a position. 
It is difficult to say precisely what "going on together" comes to, since togetherness is a rather vague idea, and "going on," is never anything other than going on with some specific task, activity, project, or endeavor (or combination thereof). Likewise, the developments--call them interruptions - that can lead to the feeling that we need to figure out how to go on together can take many forms and can be perceived in many different ways. It helps to consider some examples. The following cases are only used to illustrate some different categories of activities and interruptions - they're not necessarily very realistic. In several it should be clear that those involved shouldn't place their hopes in reasoning together, but we can learn some important lessons about the strategy we're considering by asking how it would go if they decided to try it anyway. If the examples and thought experiments that follow suggest a plausible account of how reasoning works, then the concern I have in mind will become clear very quickly.

\section{Case \#1}

Consider the most robust sort of "going on together"-a small group of people working closely together on some project. They have very similar conceptions of the project in hand, and they share the specialized know-how and understanding relevant to the sort of thing they're doing. Their behavior is interactive and complementary. We might say that they possess intersubjectivity in a very strong sense. Of course not much of our normal behavior and experience finds us so closely bound up with what others are doing. But as examples that might approximate these degrees of interdependence and coordination think of: surgeons working together on a complicated surgical procedure, a road crew installing traffic signals at an intersection, and baseball players executing a double play.

Closely interwoven activity of this sort can be disrupted in a number of ways. Consider the following:

\#la. Imagine that two surgeons discover, in the early phases of a surgical procedure, that the test results on which they had based their judgment about what the patient needed were misleading. The planned operation no longer seems like precisely the right one. Further, imagine that although they are sure that their plans require minor modifications, they cannot see immediately which among several available alternatives they should choose. They are momentarily at a loss, their smooth interaction and coordination are disrupted, and they naturally begin a brief conversation aimed at selecting the best course of action to follow. If all goes well the conversation will go smoothly - a short list of alternatives will materialize quickly, various pros and cons of the alternatives will be aired, the alternatives will be ranked (at least implicitly), and they will proceed to act on the best one-their ability to go on together restored.

If this bout of reasoning goes so well, it's because every aspect of the conversation rests heavily on a very rich common understanding. If the surgeons didn't have very similar notions of what they were doing in the first place, then 
they would not so easily have noticed that there was a need to re-examine their plans. If they could not count on being able to understand each other with minimal explanation, on ieing able to take a lot for granted in their claims and questions, then their conversation would have stalled immediately. If their common training and experience had not inculcated in them a common sense of the range of appropriate responses to situations like this one, then they would not have been able to agree so quickly on a helpful list of alternatives. And if they did not share the same expert judgment, they would not have been able to come to an agreement about the relative promise of those alternatives. Since they are experts, and since their reasoning has been based at each moment on that expertise, we say of the solution they eventually choose not just that it is a way to go on, but that it is the way to go on, the right way to carry on doing what they were doing.

$\# 1 b$. Contrast this sort of disruption with the one the same surgeons would experience if, mid-surgery, some important piece of medical equipment were to malfunction. As much as in the earlier scenario, their surgery is interrupted, and there is every interest in figuring out how to get back to it. But in this case the problem is not so clearly a surgical one. Depending on the nature of the failed equipment and on the particulars of the case, they may have to choose between trying to complete the surgery without the equipment and trying to replace it. If they choose the former, then they will have to figure out how to resume the operation under these new circumstances, and that is again a surgical problem. They may engage in reasoning that rests on their expertise as in the previous example. But if they decide that they need to replace the equipment before they can go on, their problem is no longer primarily surgical in nature. That is, they won't be able to rely on their shared medical expertise to figure out how to get back to their medical procedure, how to restore their coordination. It does not follow that the surgeons will be at a complete loss, for if they know their way around an operating room, and around a hospital, they will have other competences that they can rely on. For example, we can expect them to have in common whatever "auxiliary" competence it is by which a surgeon requests, orders, finds, or in some way procures equipment needed for surgery.

Possessed of such auxiliary competences, and therefore being acquainted with several methods for obtaining the equipment they need, we might find the surgeons engaging in a brief consideration of each of the options, reasoning in just the way that they did in our earlier example. This episode of reasoning, no less than the other, rests heavily on what they both understand, on what they both know how to do. If one of the surgeons did not have these competences, perhaps because he was new to the hospital and its particular procedures, he would be completely unable to help decide how to obtain the equipment.

$\# 1 c$. Consider one last kind of disruption that our surgeons might face. Imagine that in the middle of their surgery they are interrupted by a hospital-wide loss of power. After doing what they can to sustain their patient, they are confronted with 
a problem which is not only not primarily medical, but it doesn't even seem to fall under the "jurisdiction" of the sorts of auxiliary skills that we expect surgeons to have. Nothing in their common training or experience gives them a sense of how to solve this sort of problem. We would expect to find them asking, "What do we do now?" but we shouldn't expect them to get very far towards an answer by exchanging and assessing reasons. Suppose they decide to come up with a list of alternative methods for restoring power to the hospital. Where will such alternatives come from? And if they do manage to compile a short list, how will they know what to count for or against each of the various options? If ever there were a case in which someone should seek outside expertise, this is one. There is a correct way to restore power, but our surgeons don't know anything about it. Until someone else restores power to the hospital, it may be that they best they can do is to try to keep their patient alive. Perhaps they'll reason about that, but that's a new problem. The point is that they are not at all in a position to reason their way past the original interruption.

In this sort of case we can see especially well that reasoning together is not some sort of magically creative act that always produces efficacious results. It is rather a way of drawing on shared resources, and as those resources get thinner, reasoning loses traction. We can restore coordination by reasoning as long as we have a great deal of shared understanding and know-how-the kind of commonality that comes from being smoothly engaged together in some activity. When our activity is brought to a halt by circumstances which that activity's skill does not prepare us for, then we need to find some other relevant competence we share, or else try something besides reasoning together.

\section{Case \#2}

Of course many of our cooperative endeavors find us working together less closely than surgeons. Consider the various groups of contractors who work together to build a house. Plumbers, roofers, bricklayers, carpenters, electricians, and others work "together" in the sense that they are all working on the same project, are all partly responsible for how it turns out. To some extent they depend on each other's work-roofers need the beams assembled by the carpenters, and so on. They are also working in fairly close proximity, so they need to be able to stay out of each other's way. In short, their activities are loosely coordinated. Nevertheless, their activities are fairly distinct-they require different training, different tools, different materials, different methods, and they can be performed, at any given moment, independently of each other. Of course, just as with those whose tasks are more closely intertwined, there can arise a breakdown in the coordination with which the building contractors do their jobs. And in such cases they can resort to reasoning to try to restore that coordination.

\#2a. Imagine that in the course of building a house the various contractors find that due to some obscure zoning regulations the blueprints need to be altered 
somewhat. Imagine further that while it's clear that at least some of the work that had been done will need to be "undone," there are several options for how to accomplish this, including demolishing the structure and starting over. In any case, the new plans will require a whole new set of protocols, a new scheduling of tasks, a new and different list of tasks to be done. In the face of all of these options there is real uncertainty about how to proceed. Such a situation would certainly represent a break in the coordination the contractors had previously enjoyed. On the surface, the situation resembles that of the surgeons in $1 a$, since in both cases it is discovered that the trajectory of a process already under way needs to be altered in order to be completed appropriately. But that surface similarity is misleading. In the case of $1 a$, the disruption arises from within the activity being performed by the surgeons-it is specifically a surgical problem. The present scenario, on the other hand, is not a plumbing problem or a bricklaying problem or a carpentry problem or a roofing problem. It certainly puts all of those activities on hold, but it is internal to none of them. It is actually a problem with an auxiliary activity, the practice of planning and scheduling construction tasks. We can expect the contractors to share competence in this auxiliary activity, and it is this competence that will serve as the resource they draw on when they reason. In these ways the case is more like $1 b$, above. The contractors, with their separate skills, cannot together face a problem (at least with respect to house-building) like the one that comes up in $1 a$. Any failure of intersubjectivity among them all is, almost by definition, not a problem specific to any one of their specialties.

$\# 2 b$. Another sort of disruption of the contractors' coordination and general cooperation will be much harder to overcome by reasoning, and that is one that is provided for neither by their primary building skills nor by the auxiliary skills that builders typically possess. Imagine another, less likely, scenario: one night a pack of wild dogs takes up residence in the unfinished house, and in the morning the dogs energetically defend their new territory. It would be surprising indeed if instead of calling in someone with a special skill for handling wild animals, the contractors decided to try to reason their way to a solution. It would be surprising just because it isn't easy to see how anything that they rely on when they build a house "together" can guide them in this sort of situation. Since none of their skills directly address canine infestation, they may try to think up alternatives based on some other part of their experience, perhaps as pet-owners or hunters or naturedocumentary enthusiasts. How they will assess these alternatives is anyone's guess. We'll see later that recourse to reasoning in such a case is not merely unhelpful, but can be positively pernicious. It's enough here to note that the scenario most resembles $l c$, above. The contractors share too little in the way of wild-animalmanagement-skills to engage in any useful reasoning about it, just as the surgeons cannot reason their way to restored power. This is not to say, of course, that if they persist they will not successfully come up with a way to remove the dogs. But since their solution will be drawn from almost none of the right sort of shared understanding, any effectiveness they enjoy will most likely be a matter of luck. 
Like the case described in $I c$, this one seems bizarre, too unlikely. But any interruption that calls on none of the competences of those who work together is bound to seem bizarre. Our preparation normally extends to the sorts of situations we would encounter in the normal course of things, but it rarely extends farther. Precisely the same thing is true about the limits of useful reasoning.

\section{Case \#3}

In Cases 1 and 2, the people who are "working together" are related in that they are intentionally contributing to some common goal. We can plausibly say that the surgeons in case 1 are not only working together, but further-they are performing the same activity, drawing in complementary ways on precisely the same primary skills to achieve their common goal. The builders in Case 2 are not so closely interrelated. They are aiming at a common goal, but they are exercising a variety of different primary skills to accomplish that goal. If we imagine a continuum that describes the degree of inter-relatedness among individuals in virtue of the skills they are exercising in a given situation, the surgeons in Case 1 would represent one extreme. The builders are not quite so inter-related, so they would not occupy the same extreme position on the scale.

Quite far in the direction of the other extreme we find cases that display a much lower degree of inter-relation, cases in which the idea of "restoring interrupted coordination" takes on a very different quality. Sometimes, in extraordinary circumstances we find ourselves called together to figure out "how to go on" even though until that moment we were only going on together in the thinnest possible sense. It may be, for example, that we discover that we have a common interest in addressing something that appears to pose a common threat to our very different, barely related projects.

\#3a. Imagine a modern American city in the grip of a crime wave. Until the crime wave struck, the residents of the city went about their separate aims without much sense that they were contributing to a common goal. Suppose that these citizens do not know much about each other, have little contact, have little interaction and strive for highly individualized goals. But now that they "face a common threat," many of the residents realize that at some level there has been a common goal all along. For beneath all of their uncoordinated pursuits, they now seem to share the "project" of living together without fear for their lives or property. It is entirely possible that they never before reflected on this common purpose, never took it as a purpose at all, yet they now feel that their efforts have been interrupted, and they wish for a return to the civil order and harmony that they had been taking for granted.

The question we need to ask is: do the residents of the city have enough in common to reason fruitfully about this problem, given the fact that it interrupts not something they were doing together, but a kind of order that allowed them to do separate, virtually unrelated things in peace? As in the other cases, the answer to 
that question depends on what they have in common and how the interruption relates to what they have in common. We might want to say that the citizens have a competence in living together peacefully, but that competence may amount to nothing more than the ability each has to mind his or her own business. In other words they are interrupted not in what they do together as much as in the harmony created by each one's willingness to leave others to their own devices. If that is all they have in common, it seems to supply few of the resources necessary for reasoning together about a crime wave. They were not involved in joint crimefighting, or even crime-prevention-except perhaps insofar as a general rule enjoining everyone to mind his or her own business tends to lead to low crime rates. Case $3 a$ then, is like $I c$ and $2 b$-one in which those affected have too little in common to address, by reasoning together, the sort of "interruption" which has come up.

This is not to say that the citizens will not talk things over, nor even that they will try to come up with alternatives that they assess with reasons. We noted this earlier in Case $2 b$-the builders may try to reason together about how to evict the dogs. But whether we're talking about evicting dogs or reducing crime, the fact remains that, as non-experts in these fields, the builders and residents will spend their time most effectively if they restrict their reasoning to a subsidiary question: Who should we call about this?

Since we do indeed exchange reasons about all sorts of things in all sorts of situations, especially about things like crime, the conclusion we're approaching may seem too restrictive. Our reasoning about such things even seems successful at times. We decide to get tough on crime or to increase the size and scope of our police forces, focus on prevention, change our laws, and so on. But the point isn't that we cannot make up, rank, and implement conclusions drawn from our own imaginations. It is that our joint reasoning in such cases cannot be any better than our joint competence--and that is quite low. Our best solutions in such situations are selected not by those affected by them, but by experts we trust. If we ever do appear to reason ourselves to a conclusion in such a case, the implementation of which actually appears to solve our problem, we should consider the possibility that we got very lucky. (We should also consider the very real possibility that the solution will lead to new, unexpected problems.) The wrong tool, in the wrong hands, sometimes does the job, or seems to. But such luck comes with real costs, as we will see below.

\#3b. Consider the growing international concern about "global warming." Global warming threatens us, if it is a threat, in way very different from a crime wave. Scientists still disagree about both the extent and causes of global warming. Despite the growing worry, we do not even have a reliable diagnosis of the problem. Thus it is not clear whether or not global warming is yet affecting anyone's life. Nevertheless, in the eyes of many, global warming promises to be a genuine, largescale threat in the future. It is also thought by many to be the result of processes that are difficult to halt-if we wait until we are unambiguously suffering the effects of global warming, it might well be too late to do anything about it. Clearly 
there is plenty of room for further scientific study and reasoning on the part of specialists. But could anything come from the attempt to reach a consensus among those affected or potentially affected by global warming? Even the nominal task inter-relatedness of the inhabitants of our hypothetical city seems thick in comparison to that of the inhabitants of the whole planet. So far, global warning doesn't interrupt anything we're doing together, though it threatens to interrupt everything that everyone is doing.

In cases like this one-even more so than in cases like $1 c, 2 b$, and $3 a-$ our reasoning doesn't have much of a foothold at all. We simply do not all have enough in common, enough of the same, relevant expertise and competences, to devise and assess useful alternatives.

This is not to say that we shouldn't talk about large-scale environmental problems or threats. It is not to suggest that there is nothing we can do in concert. For one thing, we can take it as an obligation to learn as much as we can from scientists and other specialists, and to educate others about what we learn. We might well think of ourselves as obliged to build up as much intersubjectivity as possible in these ways. But the path to expertise, competence, and intersubjectivity is paved with training, practice, study, apprenticeship, immersion in a tradition or way of doing something. Reasoning together, on its own, cannot bring about any of this-it first gets its foothold once all of this is already in place.

To believe that exchanging and assessing reasons together can create competence and intersubjectivity where there was too little before is to treat our powers of articulation as if they were almost magical. It is as if we could imbue our words with the ability to inculcate understanding in someone else. But reasoning together can only bridge a gap in our shared understanding if that gap is very small compared to what we share.

The cases we have just reviewed show us something of great importance about the range of effective joint reasoning. What makes such reasoning effective is the availability of certain resources which we have at our disposal only when we are already engaged (or prepared to be engaged) together in some endeavor, and when that which interrupts us falls within the sphere of the competence we're exercising or some other which we share. Reasoning together in a fruitful way depends upon our existing shared practice, shared knowledge, and shared competence. Under the right conditions, reasoning together can restore that intersubjectivity. Under almost no circumstances can reasoning together create that intersubjectivity where it does not already exist.

\section{The Harm in Trying}

A natural response to the foregoing would be to suppose that even if reasoning together cannot get a foothold in some circumstances, there's no harm in trying. Perhaps we're even obligated, in very important situations, to try reasoning together, even if we know it is a long shot. If there's even a chance it could work, we might think, shouldn't we give it a try? But matters are not that simple. There is indeed a 
price to pay when we try to reason beyond the reach of argumentation, and unfortunately, the more successful the wrong kind of reasoning seems to be, the higher the price we pay.

Imagine a scenario in which, as we have claimed, the participants have no business trying to solve their problem by reasoning together. The house builders in Case $2 b$ present a good example. If the builders should persist in trying to figure out how to evict the wild dogs through reasoning together, one of two possible results will follow. Either they will settle on a conclusion that, once implemented, works, or they will settle on and implement one that doesn't work. In the latter case the obvious price is frustration and lost time, and perhaps a worse problem than that with which they began (perhaps they only enrage the dogs, for example). In the former case, where the builders seem to succeed, the price can be higher, if more difficult to detect- they may do lasting harm to their reasoning skills. Since the builders have, by stipulation, no expertise in dealing with wild dogs, we have to view their success as a matter of luck. When reasoners enjoy apparent success after drawing on inadequate or inappropriate intellectual or practical resources, they may develop and reinforce a number of bad habits. First of all, they may stop wondering about whether or not they do indeed have the appropriate competences. Further, they may even begin to lose sight of the whole distinction between appropriate and inappropriate expertise. They may thus fall into the kind of rationalism described by Oakeshott (1991) - they begin to expect reasoning to be able to solve any problem at all, no matter what its provenance, no matter who the reasoners. Again, insofar as such "loose-cannon" reasoning leads them to unambiguous failures, the development of these bad habits is inhibited. It is the apparent success that brings about the unfortunate positive feedback-seemingly successful ungrounded reasoning obscures the distinction between grounded and ungrounded reasoning.

Can such reasoning be genuinely, rather than merely apparently, successful? Is success in reasoning to be measured purely by whether or not the projected goal is met? The dogs are removed from the site, but is that all that counts? The answer is that it depends a great deal on what happens next. We surely won't call it a complete success if the solution they choose happens to remove the dogs but also leads to other problems they didn't have before. Of course those further problems may be very difficult to discern, since they may not arise in the form of a new canine infestation. But let's imagine some easily detected, unfortunate "side-effects" that follow from their poorlyreasoned solution. Suppose they decide to shoot the dogs. Suppose their shots harm some of their own construction equipment or some part of the structure erected so far. Perhaps they will face legal trouble for violating laws against discharging firearms within city limits, or for being cruel to animals. Perhaps they will have to deal with frightened or angry neighbors. Perhaps there will be injuries. Perhaps the builders will be fired for harming the reputation of their employer. On the one hand, none of these consequences can change the fact that the dogs have been eliminated-the wish that motivated the reasoning has been fulfilled. But on the 
other hand, their inadvisable reasoning has created new crises, crises which they may also decide to address by reasoning together.

Now we have an unhappy cycle-inadvisable reasoning, reinforced by some apparent success, leads to new crises to be addressed by more inadvisable reasoning, while the very distinction between being qualified to engage in such reasoning and being unqualified is increasingly effaced. This cycle represents serious damage to our everyday competence of knowing when reasoning is warranted. Reasoning itself comes to seem less and less like a way of repairing small gaps in intersubjectivity, and more and more like an approach to crisis management (aimed at the crises it brings about). The very idea of skill, competence, expertise, becomes obscured, perhaps lost. (For related thoughts see Campolo and Turner, 2002.)

Bad reasoning leads to poor conclusions, more bad reasoning, damaged skills, a spiral of degraded judgment, and, following the loss of the very idea of competence, the loss of competence itself. Of course all of this doesn't happen at once. It happens gradually, almost unnoticeably. But if we are correct so far, the stakes are quite high when we decide whether or not to engage in reasoning together.

Reasoning together in the absence of the proper resources leads to grief in the particular case at hand. But further, when it becomes habitual, it destroys our competence at detecting when reasoning would be inappropriate. As with any of our skills, poor practice leads to diminished abilities.

\section{Generality and Distortions}

In mundane situations, mature reasoners with healthy reasoning skills are usually competent to make a judgment about whether the best results will come from reasoning together, appealing to an expert, or following some other strategy. However, in some very important cases, just when we feel most compelled to resort to reasoning together, this competence fails us. Those cases are typically ones that involve very abstract philosophical questions or contentious moral, social, or political issues and problems. For it is in these sorts of cases that we often lack the resources to reason together effectively.

We can begin to understand what accounts for this perplexing state of affairs if we recognize that our assessments of (a) what endeavor we are engaged in at any given moment, (b) how closely we're working with others, and (c) the nature of the "interruption" we face, are highly changeable and influenced by many factors. They are, in essence, descriptions that we give to ourselves, and like any descriptions, the form they take depends a great deal on our purposes, needs, interests, beliefs, plans, and much more. This much begins to be clear in Case 3 above, where the "common threat" posed by the crime wave creates a sense of solidarity which is not based on much shared understanding or competence. It is at least possible that the city's residents will get fooled - they could end up balieving that they have far more in common than they really do. If that happened, they 
might also end up believing that they are far closer to satisfying the conditions necessary for effective reasoning than they actually are.

To get a better sense of the vagaries of these assessments, the ones upon which our judgments about whether or not to reason together are based, we can look at a more robust, yet oversimplified scenario. For example, on a farm where groups of people are performing many different tasks, a casual survey might reveal that those pulling weeds view their activity as largely distinct from that of the pepper-pickers, and vice versa. But if it were announced that everyone currently engaged in "gardening" could have the rest of the day off, we might find that in this context members of the two groups feel that they have something in common. The announcement leads them to shift their description of how much they have in common. This shift in description can work the opposite way as well. The fellow feeling of all the "gardeners" may evaporate the moment it is announced that only those picking peppers are to be given a raise in pay. Now extend the example a bit: imagine that a run of bad weather leaves the farm flooded. In this case, the members of the two groups have a mutual interest in discovering some remedy. They have something in common, and this may create in them a willingness to think of themselves as engaged in the same endeavor. Their sense of inter-relatedness has shifted, increased, in the face of a common threat. Consider another variation: imagine that at a certain point the demand for peppers drops dramatically. In this context, pepper-pickers are alone in their fear for their jobs, worries about the markets, etc. They may well have a decreased sense of inter-relatedness, of commonality.

It is important to realize about the farmers that as their sense of solidarity waxes and wanes, the actual resources available to them in the form of shared understanding remain fairly stable. The farmers are either like the surgeons working in closely-inter-related ways, or they are like the builders, carrying out their distinct, loosely-related tasks. What they have in common, the competences they actually share, change much more slowly than their level of fellow-feeling. They are, at some momentary peak of solidarity, no more equipped to reason together than when they feel no inter-relatedness at all-though in the former mood they may be much more motivated to try to reason together.

Certain kinds of interruptions can make us feel as if we have more in common than we do, but the dynamic also works in the opposite direction-the sense of solidarity we enjoy at a given moment shapes how we perceive the "event" which interrupts what we're doing, shapes our judgment about whether or not our common competences contain the resources required to overcome the interruption. It's a sort of interpretive circle.

If the above picture of reasoning makes sense, and if we do find ourselves in the sort of interpretive circle described here, then it takes few words to get at the nature of the worry I have about our well-intentioned appeals to more general common ground. 


\section{Strategic Ascent}

Our assessments of our relationship to others, the interruptions we face, etc., are not only subject to accidental changes--we try to change them whenever we suggest that disputants move to more general, common ground. Part of our goal when we make such a suggestion is to create a greater sense of solidarity than the dispute allowed. If we can see ourselves as really working toward the same ends, engaged in the same endeavor, committed to the same principles, then our disagreement represents not a clash between disparate world-views, but rather a quarrel from within a certain shared practice and tradition. From this new perspective, it is hoped, we can see that, at least to some extent, we stand on common ground - fuller agreement may eventually be possible.

When this move is used as a corrective to counter overly polarized or politicized positions, then it implicitly involves the claim that there are more resources for reasoning together than we had realized. If that claim is true, then this maneuver can be very helpful-it allows us to ground our reasoning on a more broadly shared set of commitments, beliefs, and competences. On the other hand, this claim can be made mistakenly and in those cases it is a threat to our reasoning competence. If you convince me that we have more in common than we appear to, then I might be more inclined to try reasoning together. But if you're wrong, if we do not in fact have enough in common for reasoning to be effective, then you've put your reasoning skills and mine at risk. For we will become accustomed to reasoning together where we have no business doing so, and that's a habit that reinforces itself in the ways described above.

Then again, it is worth recognizing that you might knowingly try to deceive me into believing that we have more in common than we really do. If I enter into poorly grounded reasoning with you, I may become vulnerable to your strategic sophistry. I will believe in the integrity of our reasoning process and I will believe in the legitimacy of the conclusion we reach together, yet in all of this I will have been tricked. We do not have to go far to find examples of this sort of manipulation: the manager tries to foster a sense of solidarity between herself and her employees so that none of them seriously considers organizing or joining a union; the multinational oil company tries to convince members of the public that it shares their concern about the environment in order to head off demands for tougher regulations, and so on.

Will not some of the disputants addressed in the examples with which we began feel that they have been tricked in this way? Pro-lifers will find that if they accept Dworkin's claim that the real argument is about how to honor the sanctity of life, they will be maneuvered into a distinctly pro-choice corner. After all, Dworkin eventually explains, everyone should be able to decide how to honor the sanctity of life in her own way-it's at bottom a question of religious freedom. Likewise, the researcher who favors using animals as test subjects will find that with his acceptance of the notion that animals have interests worth protecting, he is ushered quite far in the direction of an anti-animal-testing stance. After all, if animals have 
any interests worth protecting, DeGrazia claims, then "all parties can endorse and support the goal of finding ways to eliminate animal subjects' pain, distress, and suffering."

As we can see, the appeal to a more general, shared understanding is a risky (though sometimes valuable) move. When the appeal is sincere, he who makes it claims to have an accurate assessment of the degree to which the resources required for reasoning together are present, and that is a bold claim. We are probably in a position to make this claim sometimes, especially when not directly party to the controversy or discussion at hand. But in all cases we should be careful to signal that the appeal is highly provisional, tentative, even experimental. Otherwise it is either foolhardy or dishonest, and in either case it threatens our reasoning skills.

\section{References}

Campolo, Christian and Dale Turner. 2002. "Reasoning Together: Temptations, Dangers, and Cautions," Argumentation 16: 3-19.

DeGrazia, David. 1999. "The Ethics of Animal Research: What are the Prospects for Agreement?" Cambridge Quarterly of Healthcare Ethics 8: 23-34.

Dworkin, Ronald. 1994. Life's Dominion: An Argument about Abortion, Euthanasia, and Individual Freedom. New York: Vintage.

Oakeshott, Michael. 1991. Rationalism and Politics and Other Essays. (Expanded from the 1962 edition.) Indianapolis: Liberty Fund.

Warnke, Georgia. 1999. Legitimate Differences: Interpretation in the Abortion Controversy and Other Public Debates. Berkeley: University of California Press.

Wright, Larry. 1995. "Argument and Deliberation: A Plea for Understanding," Journal of Philosophy 92: 565-585.

Wright, Larry. 1999. "Reasons and the Deductive Ideal," Midwest Studies in Philosophy 23: 197-206.

Wright, Larry. 2001. "Justification, Discovery, Reason, and Argument," Argumentation 15:97. 104.

Wright, Larry. 2002. "Reasoning and Explaining," Argumentation 16: 33-46.

Christian Campolo Department of Philosophy

Hendrix College

1600 Washington Ave.

Conway, AR 72032 